\title{
PEMBUATAN MEDIA PEMBELAJARAN MERAKIT PC (PERSONAL COMPUTER) DENGAN VIRTUAL REALITY MENGGUNAKAN APLIKASI MOBILE
}

\author{
Estu Sinduningrum ${ }^{1}$, Fahmi Rais ${ }^{2}$, Atiqah Meutia Hilda ${ }^{3}$ \\ ${ }^{1,2,3}$ Teknik Informatika,Universitas Muhammadiyah Prof. Dr. HAMKA \\ Jakarta,Indonesia
}

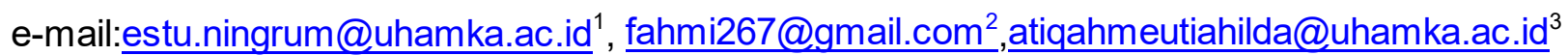

\begin{abstract}
Abstrak
Pelajaran merakit komputer saat ini, yang ada di tingkat SMK terutama SMKN 3 Kota Bekasi masih menggunakan komponen komputer yang sudah tidak berfungsi. Biaya untuk menyediakan komponen-komponen komputer yang sesuai dengan generasi terbaru sangat memberatkan pihak sekolah. Para siswa hanya dapat melihat tanpa ada perakitan secara langsung, serta pengenalan komponen komputer yang hanya dijelaskan secara konvensional yaitu, dengan cara lisan atau teori saja, hal tersebut membuat jenuh dan bosan. Melihat fenomena tersebut, menginspirasi peneliti untuk membuat sebuah media pembelajaran menggunakan teknologi Virtual Reality yang interaktif dan mudah digunakan, sehingga dapat meningkatkan minat dan ketertarikan siswa terhadap mata pelajaran merakit komputer. Metode yang digunakan pada penelitian ini adalah Research and Development (R\&D) yang dimulai dari identifikasi masalah, pengumpulan data, sampai produksi prototipe akhir. Hasil penelitian yang didapatkan dengan perhitungan menggunakan skala likert tercapai kepuasan dengan nilai rata-rata dari tiga penguji, yaitu: para ahli $=75 \%$, guru $=82.5 \%$, dan siswa $=84.479 \%$.
\end{abstract}

Kata kunci: Media pembelajaran, Interaktif, Virtual Reality, Perakitan Komputer

\begin{abstract}
The current computer assembly lesson, which is at the vocational level, especially SMKN 3 Bekasi City still uses computer components that are no longer functioning. The cost of providing computer components in accordance with the latest generation is very burdensome to the school. The students who just only can see without direct assembly, as well as the introduction of computer components that are only explained verbally or in theory alone are saturated and bored. Seeing this phenomenon, inspiring researchers to create a learning media that aims to make Virtual Reality as a learning media that is interactive and easy to use so that it can increase students' interest and interest in the subject of assembling computers. The method used in this research is Research and Development (R\&D) which starts from problem identification, untill to the final prototype production. The results obtained by calculations using a Likert scale achieved satisfaction with the average value of three examiners, namely: an experts $=75 \%$, the teachers $=$ $82.5 \%$, and the students $=84.479 \%$.
\end{abstract}

Keywords: Learning Media, Interactive, Virtual Reality, Computer Assembly

\section{PENDAHULUAN}

Kemajuan IImu Pengetahuan dan Teknologi tentunya diikuti dengan berkembangnya ilmu di bidang pendidikan. Berbagai cara dan metode digunakan untuk meningkatkan kualitas dalam pendidikan. Salah satu upaya yang dapat dilakukan adalah dengan meningkatkan kualitas media pembelajaran yang digunakan. Media dalam pembelajaran merupakan hal yang tentunya dapat mendukung efektifitas serta ketertarikan siswa dalam memahami pelajaran yang ada. Dengan adanya media yang baik dan menarik, maka minat siswa dalam mengikuti dan mengolah 
pembelajaran yang diberikan akan ikut serta meningkat. Pelajaran merakit komputer di Sekolah terutama di Sekolah Menengah Kejuruan (SMK) Negeri 3 Kota Bekasi merupakan salah satu indikator pencapaian ketuntasan kompetensi dasar dari Teknik Jaringan dan Komputer. Yang terjadi saat ini, pada saat pelajaran tersebut siswa hanya diperlihatkan saja secara langsung beberapa komponen komputer yang sudah tidak berfungsi, sehingga membuat proses belajar mengajar menjadi kurang efektif, dan terdapatnya siswa yang kurang tertarik, yang pada akhirnya kurang memahami dengan materi pada komponen pada komputer dan cara merakitnya, khususnya pada komponen komputer generasi terbaru.

Penelitian mengenai media pembelajaran dengan menggunakan teknologi Virtual Reality telah banyak dilakukan untuk membantu permasalah atau kendala terhadap pengenalan atau pembelajaran terhadap sebuah objek tertentu. Hasil yang didapatkan dari penelitian lain, yaitu pembelajaran dengan menggunakan teknologi Virtual reality selalu mendapatkan respone baik, dibandingkan cara konvensional (hanya teori atau penyampaian bahan ajar dengan lisan), cara "Pembelajaran kontekstual dapat dilakukan secara REALITA, yaitu Related, Easy, Applying, Lesson, Interesting, Transferring, Actual" [1]. Perlu dikemukakan pula bahwa kegiatan pembelajaran adalah suatu proses komunikasi. Dengan kata lain, kegiatan belajar melalui media terjadi bila ada komunikasi antar penerima pesan $(P)$ dengan sumber (S) lewat media (M) tersebut. Namun proses komunikasi itu sendiri baru terjadi setelah ada reaksi balik (Feedback). Berdasarkan uraian di atas maka secara singkat dapat dikemukakan bahwa media pembelajaran itu merupakan wahana penyalur pesan atau informasi belajar [2].

Penelitian pertama mengenai pemanfaatan Virtual Reality sebagai Media Pembelajaran Interaktif untuk sistem tata surya telah dilakukan oleh Ade Randi, pada tahun 2017. Pada penelitiannya, metode yang digunakan adalah penelitian kuantitatif dimana strategis yang digunakan adalah Design and Creation. Penelitian ini merancang dan membangun aplikasi sebagai Media Pembelajaran sistem tata surya yang memanfaatkan Virtual Reality berbasis Android. Pemodelan tata surya pada aplikasi ini menggunakan Blender 3D, Game Engine yang digunakan yaitu Unity3D. berdasarkan hasil pengujian, $80 \%$ responden menyatakan aplikasi ini mudah digunakan. $53 \%$ responden menyatakan aplikasi ini sangat bermanfaat [2].

Penelitian kedua, yaitu media pembelajaran dengan Virtual Reality telah dilakukan oleh Nurhadi Zakiyan, Estu Sinduningrum, dan $\mathrm{H}$. Irfan pada tahun 2017. Dalam jurnal nya, penelitian ini merancang sebuah media pembelajaran virtualisasi dari obyek Masjidil Haram menggunakan Virtual Reality yang beroperasi pada Smartphone. Media pembelajaran ini dibuat sebagai pembekalan dan pengetahuan mengenai lokasi tentang Masjidil Haram yang berperan sangat penting untuk para calon jamaah haji dan juga bagi pengetahuan umat muslim. Pemodelan pada media pembelajaran ini dibuat di Google Sketchup 3D, dan memprosesnya menjadi sebuah Virtual Reality menggunakan Game EngineUnity. Bedasarkan pengujian yang telah diimplementasikan di Kementerian Agama kota Tangerang, dapat disimpulkan bahwa visualisasi Masjidil Haram dengan Virtual Reality sudah menarik dan mudah dimengerti oleh masyarakat dengan nilai index sebesar 90\% [3]. Penelitian ketiga yang dilakukan oleh Servasius Vidiardi tentang pengembangan Museum Virtual Interaktif menggunakan teknologi desktop Virtual Reality Pada Museum Ranggawarsita bertujuan untuk mempelajari obyek yang ada di Museum, dan juga dapat memberikan inisiatif tentang penggunaan teknologi masa kini khususnya multimedia untuk mengemas potensi Museum secara lebih atraktif, dan kekinian. Penelitian ini juga menggunakan Blender 3D sebagai aplikasi untuk 3D Modelling dan Unity $4.3 \quad 4 \mathrm{f} 1$ sebagaiGame Enginenya. Berdasarkan pengujian yang telah dilakukan penelitian ini, berhasil membuat sebuah desktop Virtual Reality yang 
bernama Museum Virtual Interaktif Ranggawasira (MuVIR) yang dikembangkan ke Third Person Controller yang memiliki nilai sangat layak yaitu sebesar $83,833 \%$ [4]. Pada penelitian ini akan memperbaiki cara pembelajaran dari cara konvensional, menjadi pembelajaran interaktif dengan menggunakan teknologi saat ini, yaitu Virtual Reality.

Dengan itu penulis akan melakukan penelitian dengan judul "Pembuatan Media Pembelajaran Merakit PC (Personal Computer) Dengan Virtual Reality menggunakan Aplikasi Mobile".

\section{METODE}

Virtual Reality adalah teknologi berbasiskan komputer yang mengkombinasikan perangkat khusus input dan output agar pengguna dapat berinteraksi secara mendalam dengan lingkungan maya seolah-olah berada pada dunia nyata. VR memungkinkan pengembang dalam membuat lingkungan virtual dengan cara potensial sebagai simulasi. Visualisasi-visualisasi yang terjadi pada dunia maya (virtual world) pada saat menggunakan VR terdiri dari secara pandangan (visual), secara pendengaran (auditory) ataupun rangsangan-rangsangan lainnya[5].

Lingkungan yang ditirukan dapat menjadi mirip dengan dunia nyata, sebagai contoh, simulasi untuk pilot atau pelatihan pertempuran, atau dapat sangat berbeda dengan kenyataan, seperti di VR game. Dalam praktik, sekarang ini sangat sukar untuk menciptakan pengalaman Realitas maya dengan kejernihan tinggi, karena keterbatasan teknis atas daya proses, resolusi citra dan lebar pita komunikasi. Bagaimanapun, pembatasan itu diharapkan untuk secepatnya diatasi dengan berkembangnya pengolah, pencitraan dan teknologi komunikasi data yang menjadi lebih hemat biaya dan lebih kuat dari waktu ke waktu.

$\begin{array}{lrrr}\text { Klasifikasi } & \text { tersebut } & \text { kemudian } \\ \text { dikenal dengan } & \text { nama } & \text { "Kerucut }\end{array}$ pengalaman" dari Edgar Dale dan pada saat itu dianut secara luas dalam menentukan alat bantu yang paling sesuai untuk pengalaman belajar. Dalam kaitannya dengan fungsi media pembelajaran, dapat ditekankan beberapa hal berikut ini: [5]

Virtual Reality adalah teknologi berbasiskan komputer yang mengkombinasikan perangkat khusus input dan output agar pengguna dapat berinteraksi secara mendalam dengan lingkungan maya seolah-olah berada pada dunia nyata. VR memungkinkan pengembang dalam membuat lingkungan

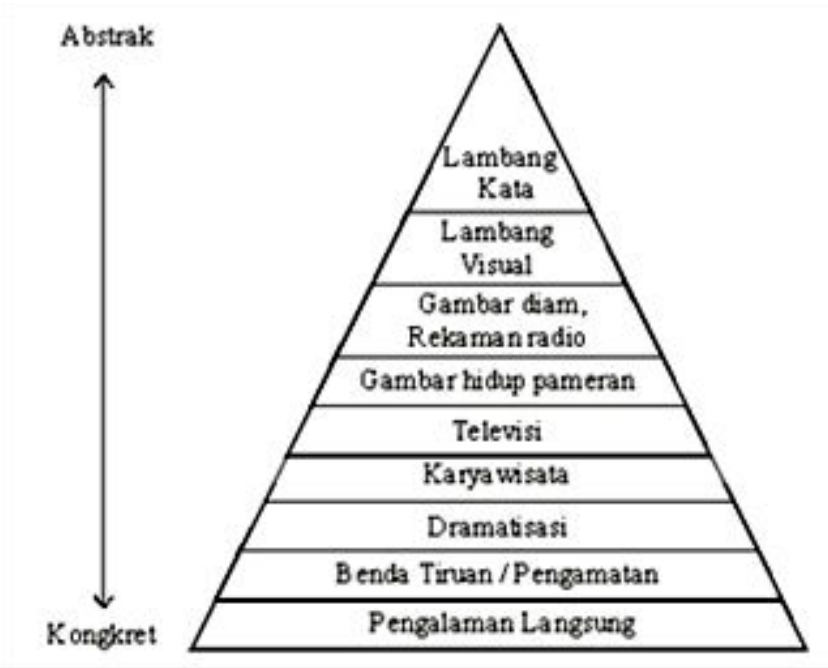

Gambar 1. Kerucut Pengalaman Edgar Gale [5]. 
virtual dengan cara potensial sebagai simulasi.

Visualisasi-visualisasi yang terjadi pada dunia maya (virtual world) pada saat menggunakan VR terdiri dari secara pandangan (visual), secara pendengaran (auditory) ataupun rangsangan-rangsangan lainnya[5].

Realitas maya dengan kejernihan tinggi, karena keterbatasan teknis atas daya proses, resolusi citra dan lebar pita komunikasi. Bagaimanapun, pembatasan itu diharapkan untuk secepatnya diatasi dengan berkembangnya pengolah, pencitraan dan teknologi komunikasi data yang menjadi lebih hemat biaya dan lebih kuat dari waktu ke waktu[6]. Research and Development (R\&D) adalah metode penelitian yang digunakan untuk menghasilkan produk tertentu dan menguji keefektifan metode tersebut. Dalam bidang pendidikan, penelitian dan pengembangan atau Research and Development (R\&D), merupakan metode penelitian yang digunakan untuk mengembangkan atau memvalidasi produk-produk yang digunakan dalam pendidikan dan pembelajaran. Dari uraian tersebut maka dapat ditarik kesimpulan bahwa Research and Development adalah metode penelitian yang bertujuan untuk menghasilkan produkproduk tertentu serta menguji validitas dan keefektifan produk tersebut dalam penerapannya

[7](http://www.aftanalisis.com).

Produk tersebut tidak selalu berbentuk benda atau perangkat keras (hardware), seperti buku, modul, alat bantu pembelajaran di kelas atau di laboratorium, tetapi bisa juga perangkat lunak (software), seperti program komputer untuk pengolahan data, pembelajaran di kelas, perpustakaan atau laboratorium, ataupun
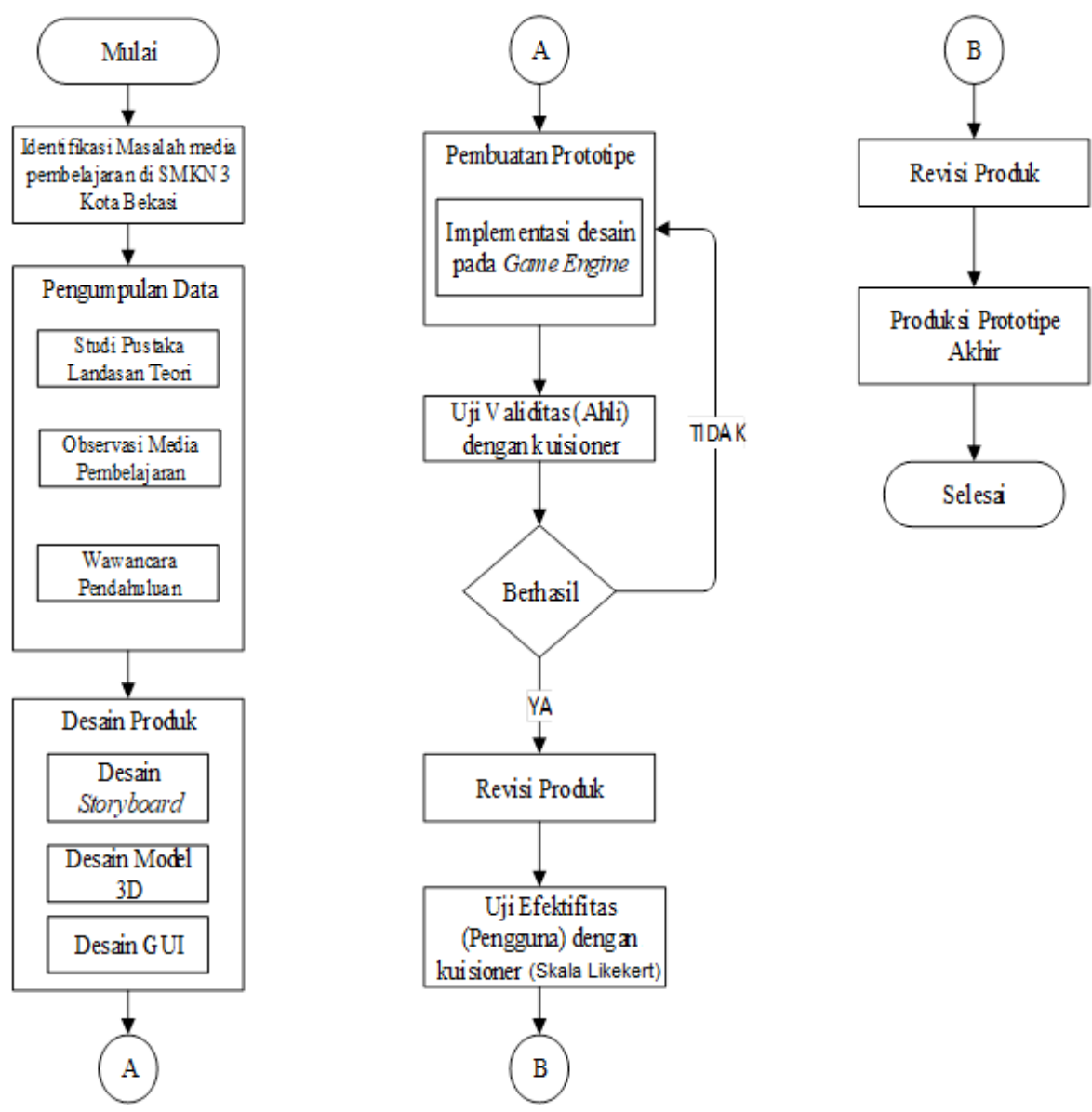

Gambar 2. Langkah-langkah Penggunaan Metode R\&D 
model-model pendidikan, pembelajaran, pelatihan, bimbingan, evaluasi, sistem manajemen, dan lain-lain[8]. Pada gambar 1, merupakan klasifikasi "Kerucut pengalaman" dari Edgar Dale dan pada saat itu dianut secara luas dalam menentukan alat bantu yang paling sesuai untuk pengalaman belajar.

Metode yang digunakan dalam penelitian ini menggunakan pendekatan penelitian pengembangan (Research and Development). Alur penelitian ditunjukkan pada gambar 2. Penjelasan gambar 2, yaitu:

\section{A. Analisa Masalah}

SMKN 3 Kota Bekasi memiliki komponen perangkat komputer yang sudah tidak berfungsi. Hal tersebut dapat dimanfaatkan siswa sebagai media pembelajaran. Dalam pelaksanaannya sebelum melaksanakan praktek secara langsung, diperlukan pemahaman dasar perangkat dan teknik serta skema perakitan komputer.

Virtual Reality menjadi salah satu alternatif yang dipakai dalam membantu para siswa/siswi untuk belajar teknologi dengan cara dan pengalaman yang berbeda serta lebih interaktif. Dengan merancang dan mengemas media pembelajaran demikian akan dapat menghadirkan komponen-komponen komputer generasi terbaru secara visual, memberikan informasi yang berisi ilmu praktek merakit komputer (PC) sesuai dengan ketentuan yang ada di sekolah.

\section{B. Analisa sistem}

Interaksi manusia dan komputer adalah suatu disiplin ilmu yang mengkaji komunikasi ataupun interaksi antar pengguna dengan sistem komputer. Peran utama dari interaksi manusia dan komputer adalah untuk menghasilkan sistem yang mudah digunakan, aman, efektif dan efisien. Dalam interaksi manusia dan komputer terdapat tiga komponen yang terlibat dalam sistem antara lain pengguna sistem, model interaksinya dan sistem yang akan digunakan[9]. Adapun Analisa kebutuhan perangkat keras yang dibutuhkan pada penelitian ini, yaitu:

a. Spesifikasi minimal PC

- Processor : Intel i3-4170 (3M cache, $3.70 \mathrm{GHz}$ )

- RAM : 4 Giga Byte

- Hard Disk : Kartu grafis deng-an DX9

b. Spesifikasi minimal Smartphone

- Operating System : Android 4.0 versi Kitkat

Analisa kebutuhan perangkat lunak

- Windows 10

- Unity 3D 2018

- Blender 2.79

- Adobe Photoshop CC 2019

\section{Perancangan Use Case Diagram}

Use case diagram merupakan pemodelan untuk kelakuakn (behavior) sistem informasi yang akan dibuat. Use case digunakan untuk mengetahui fungsi apa saja yang ada di dalam sistem informasi dan siapa saja yang berhak menggunakan fungsi-fungsi tersebut[10].

Pada gambar 3 menunjukan interaksi antara pengguna dengan sistem, mulai dari membuka aplikasi, lalu dilanjutkan ke mode belajar, mode simulasi, dan menutup aplikasi.

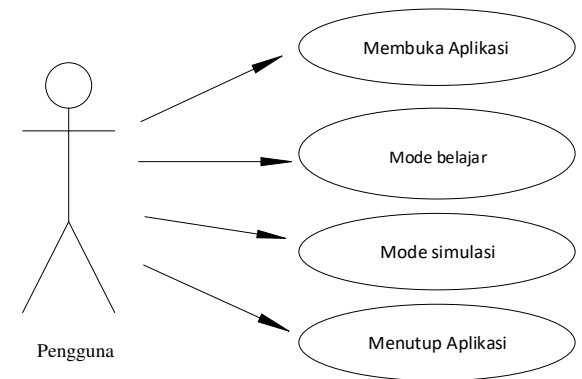

Gambar 3. Use Case Diagram Aplikasi media pembelajaran

\section{Perancangan Diagram Statechart}

Pada diagram statechart akan menunjukan keadaan-keadaan yang mungkin terjadi atau dialami oleh objek. Berikut ini adalah penggambaran Statechart diagram pada Aplikasi media pembelajaran. 
1. Statechart Diagram Membuka Aplikasi Pada gambar 4 adalah proses membuka aplikasi, terdapat 3 keadaan yang yang terjadi sampai akhir proses. Dimulai dari ketika pengguna menyambung joystick ke perangkat Android, menggunakan VR box dan langsung membuka aplikasi, dan akan menampilkan main menu.

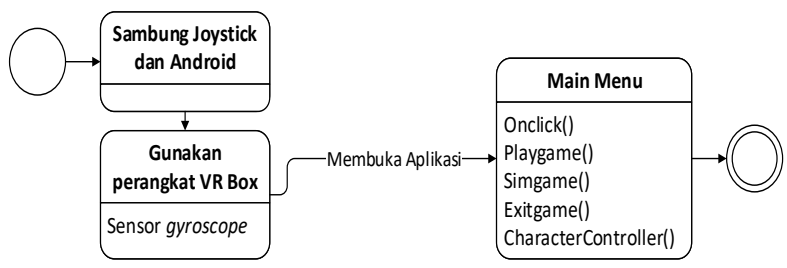

Gambar 4. Statechart diagram membuka aplikasi pembelajaran

\section{Statechart Diagram Mode Belajar}

Pada gambar 5 merupakan proses mode belajar, terdapat 5 keadaan yang yang terjadi sampai akhir proses. Dimulai dari ketika sistem menampilkan komponen komputer 3D sampai berpindah scene ke quiz.

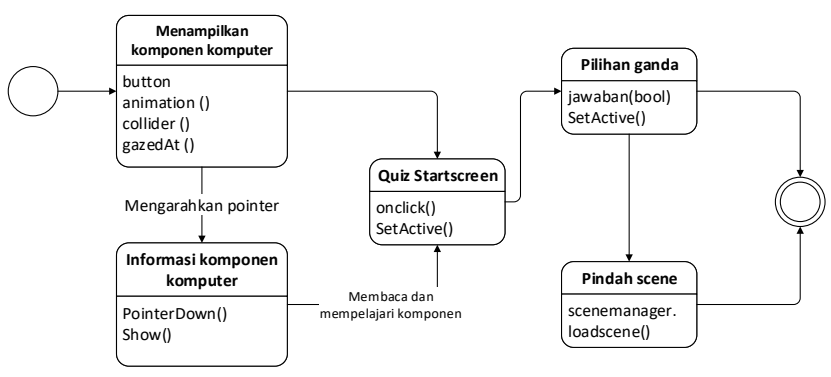

Gambar 5. Statechart diagram mode belajar

3. Statechart Diagram Mode Simulasi

Pada gambar 6 adalah proses mode simulasi, terdapat 4 keadaan yang yang terjadi sampai akhir proses.Dimulai dari keadaan scene simulasi telah aktif, sampai menampilkan canvas berhasil.

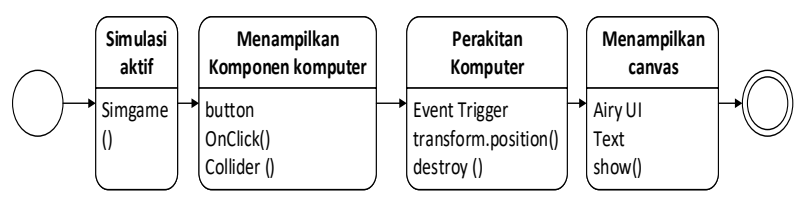

Gambar 6. Statechart diagram mode simulasi

\section{E. Perancangan Component Diagram}

Pada gambar 7 merupakan komponen diagram yang menggambarkan alokasi semua Class dan Object kedalam komponen dalam desain fisik system software, termasuk pengaturan dan kebergantungan antar komponen software.

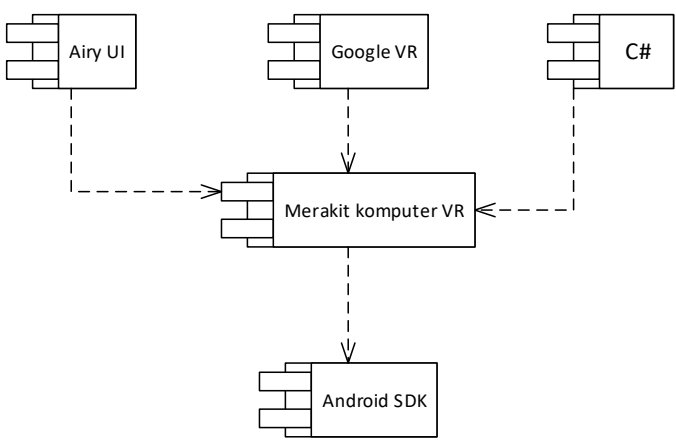

Gambar 7. Komponen diagram Media Pembelajaran

\section{F. Perancangan Deployment Diagram}

Deployment Diagram menunjukkan susunan fisik sebuah sistem, menunjukkan bagian perangkat lunak mana yang berjalan pada perangkat keras. Gambar 8 merupakan deployment diagram media pembelajaran dengan VR.

\section{G. Tahap Produksi}

\section{a) Desain Storyboard}

Desain sebuah storyboard yang menentukan tampilan layar per-layar agar media pembelajaran yang di desain lebih terstruktur. Dan storyboard ini berisikan deskripsi pada setiap layar yang bertujuan untuk menjelaskan/menggambarkan media pembelajaran yang dibuat.

b) Desain Model 3D

Desain model 3D untuk bagian komponen utama dalam perakitan komputer dan juga model 3D lingkungan menggunakan perangkat lunak Blender.

c) Desain GUI Aplikasi

Bertujuan untuk memberikan gambaran tentang sistem yang akan dibangun dan hasilnya sesuai dengan kebutuhan. Dan dengan memperhatikan desain tampilan 


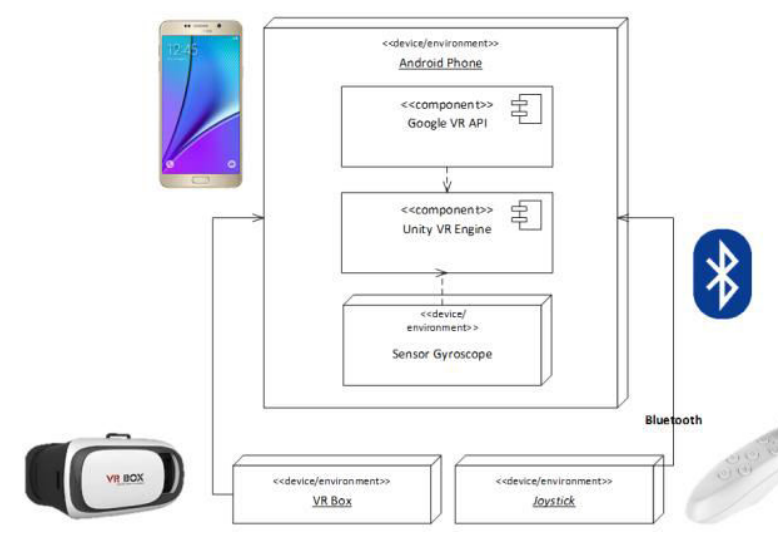

Gambar 8. Deployment Diagram Media

Pembelajaran dengan VR

sehingga mempermudah pengguna dalam menggunakan aplikasi ini.

\section{H. Tahap Uji Validasi \& Efektifitas}

Tahap uji validasi dilakukan untuk pengujian aplikasi yang dilakukan menggunakan metode black box untuk memeriksa apakah setiap komponen yang telah dibuat di dalam sistem telah bekerja dan proses sistem ini dapat dilihat pada tabel 2. Black box testing digunakan bertujuan untuk mengetahui apakah fungsi-fungsi pada aplikasi telah berjalan sesuai dengan fungsinya dan mengevaluasi kesesuaian aplikasi dengan kebutuhan pengguna [11].

Tahap uji efektifitas menggunakan skala likert, dimana skala ini digunakan untuk mengukur sikap, pendapat, dan persepsi seseorang atau sekelompok orang tentang fenomena sosial. Dengan Skala Likert, variabel yang akan diukur dijabarkan menjadi indikator variabel [12].

\section{HASIL DAN PEMBAHASAN}

Hasil dari pembuatan aplikasi terdiri dari 3 tahap, yaitu:

a) Hasil dari storyboard, yaitu:

Storyboard merupakan kumpulan sketsa gambar yang disusun secara berurutan dan disesuaikan dengan konsep awal sehingga ide cerita aplikasi ini

dapat disampaikan dengan mudah. Storyboard untuk Aplikasi media pembelajaran ini dapat dilihat pada tabel 1.

Tabel 1. Storyboard Aplikasi Media Pembelajaran merakit komputer.

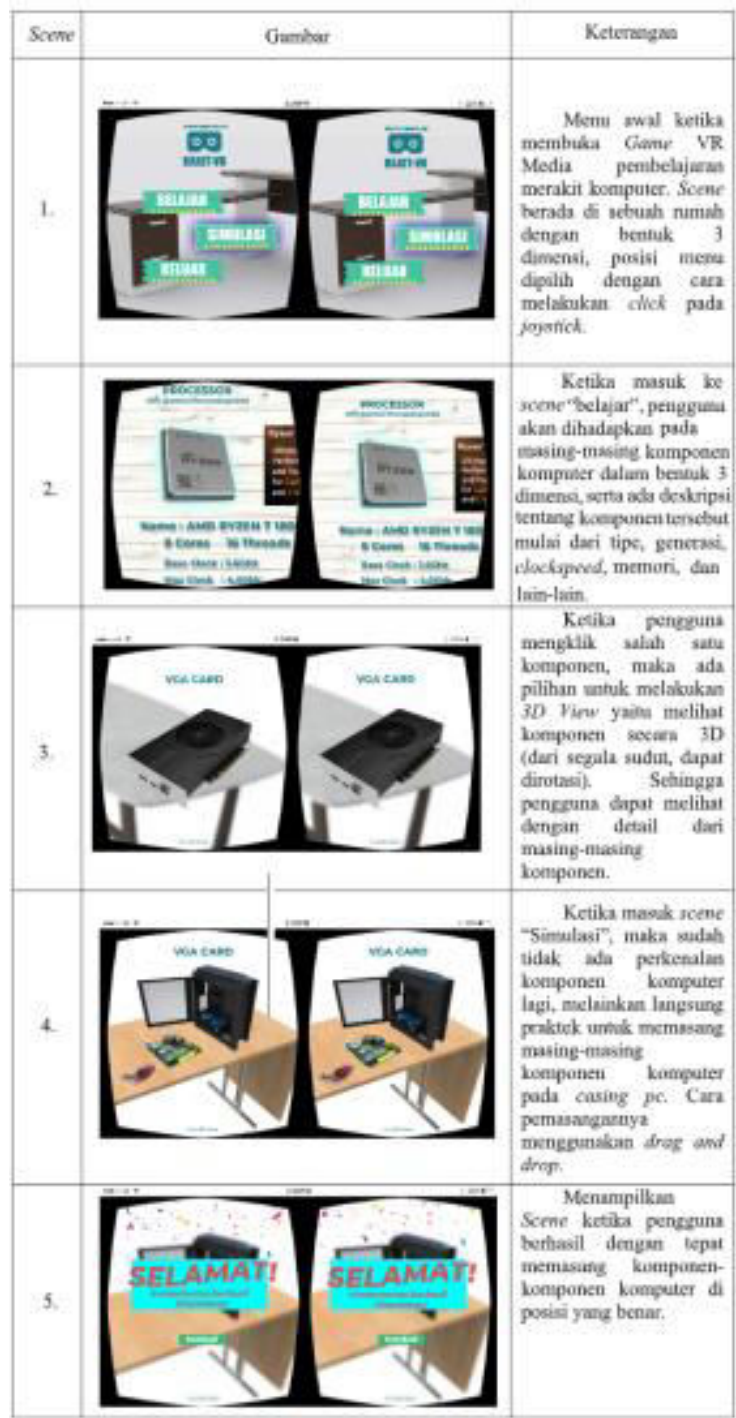

b) Hasil dari Desain Model 3D Desain Model 3D merupakan tahap selanjutnya setelah perancangan selesai maka akan dilanjutkan dengan pembuatan Desain menu utama, Object Environment, Button dan Penganimasian menggunakan Game Engine Unity. 


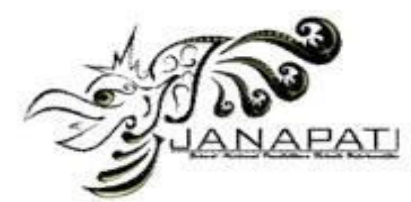

1) Tampilan Pemodelan Motherboad pada Blender
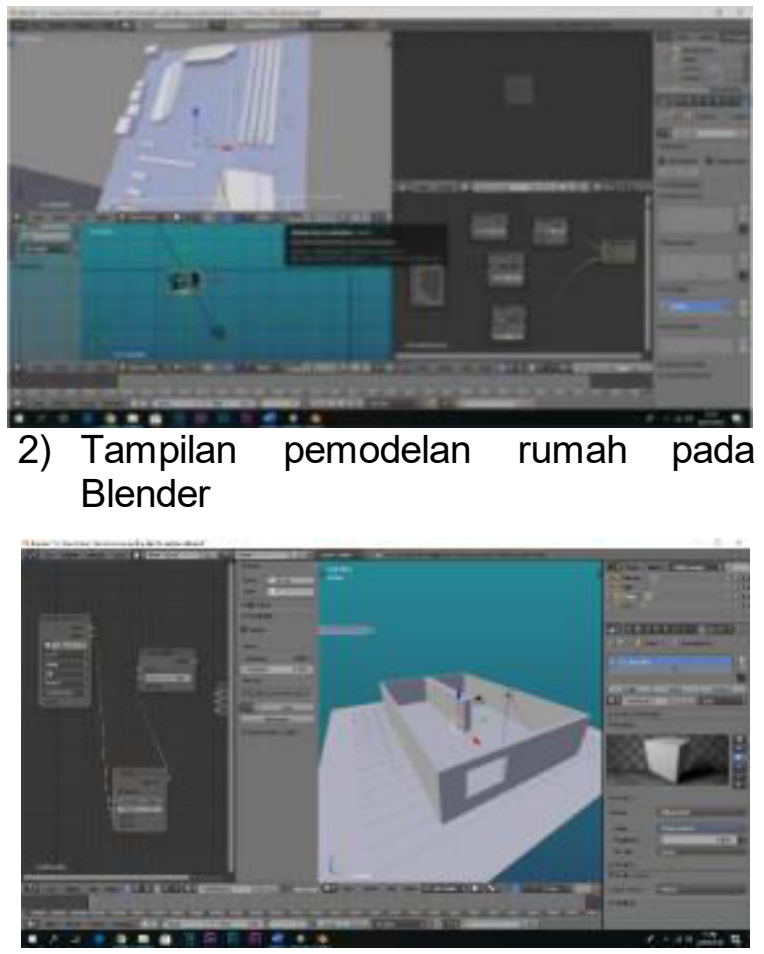

3) Tampilan produksi mode belajar di Unity.

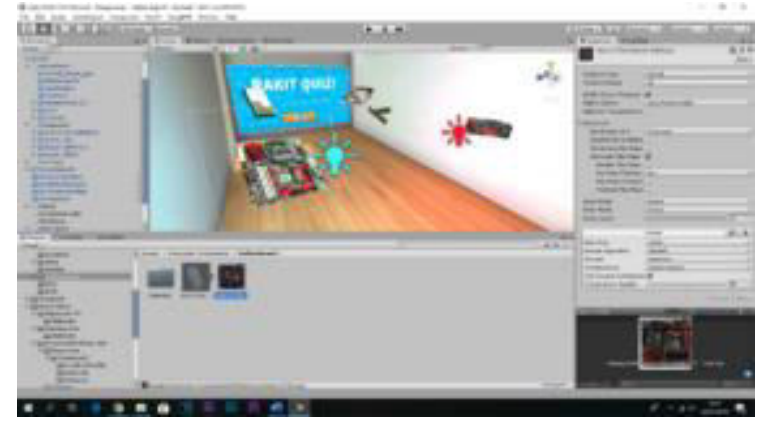

c) Hasil pengujian dan implementasi aplikasi media pembelajaran merakit PC (Personal Computer) dengan VR yang telah dibuat untuk siswa SMKN 3 Kota Bekasi (desain GUI Aplikasi), yaitu:

1) Implementasi Antarmuka Menu

Untuk memulai pembelajaran dan simulasi merakit $\mathrm{PC}$, tampilan menu utama akan menampilkan 3 button yaitu belajar, simulasi, dan keluar.

\section{2) Implementasi Mode Belajar}

Pada mode belajar ini, pengguna seakan akan berada di sebuah

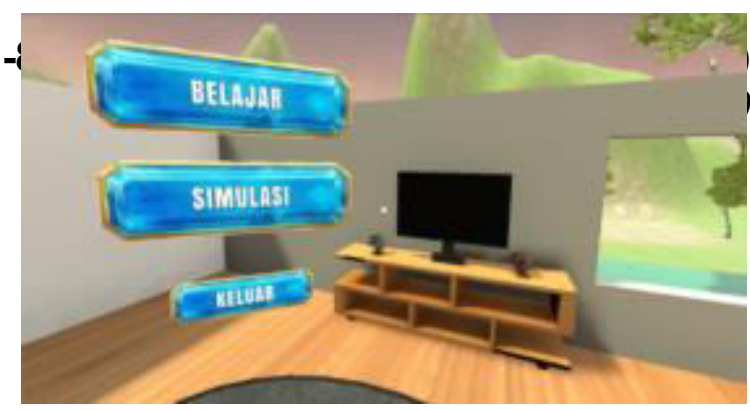

ruangan dengan berbagai macam komponen komputer di sekelilingnya. Agar dapat mempelajari masingmasing komponen komputer pengguna hanya mengarahkan pointer pada objek 3D nya lalu akan muncul canvas berisikan deskripsi dari komponen komputer tersebut.

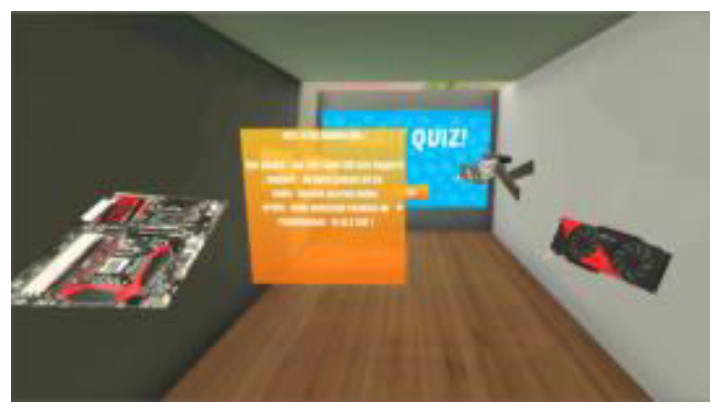

3) Implementasi Mode Simulasi

Pada mode simulasi ini pengguna dihadapkan dengan komponen komputer yang akan dirakit yang ada pada di atas sebuah objek meja, selain itu juga ada casing PC tempat dimana komputer akan dirakit.

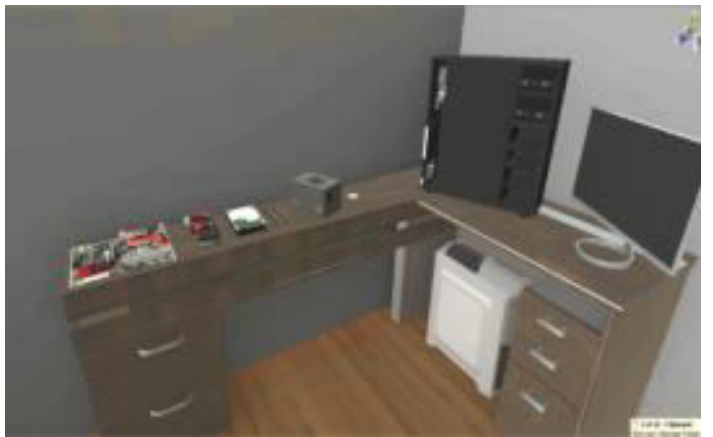

Pengujian aplikasi dilakukan dengan 2 tahap, yaitu:

1). Pengujian kerja aplikasi dengan metode black box.

2). Pengujian tingkat kepuasan dari pengguna aplikasi, memakai kuesioner dihitung dengan skala likert.

Hasil dari pengujian kerja aplikasi yang dilakukan menggunakan metode black box (tabel 2). 
Tabel 2. Hasil Pengujian Kerja Aplikasi.

\begin{tabular}{|c|c|c|c|}
\hline Menu yaing divej! & Pengujian & Hassil & Keterangan \\
\hline \multirow{3}{*}{ Main mern } & Memilih humow & $\begin{array}{l}\text { Autbou dapes di klik dan } \\
\text { berpindah scene sesuai } \\
\text { nama Aumon. }\end{array}$ & Berhasil \\
\hline & Pergerakan & $\begin{array}{l}\text { Objek player dapat } \\
\text { bergerak sesuai dengan } \\
\text { beinginan pengguna. }\end{array}$ & Berhasil \\
\hline & $\begin{array}{l}\text { Kompanen } \\
\text { kerengular 3D }\end{array}$ & $\begin{array}{l}\text { Aplikasi menampilkan } \\
\text { macam-macam objek 3D } \\
\text { komponen komputer. }\end{array}$ & Berhasil \\
\hline \multirow{3}{*}{ Mede belajar } & $\begin{array}{l}\text { Mempelajari } \\
\text { rincian komponen }\end{array}$ & $\begin{array}{l}\text { Deskripsi dan spesifikasi } \\
\text { koemposen komputer } \\
\text { tampil ketika pointer } \\
\text { diarahkan ke komponen } \\
\text { tersebut. }\end{array}$ & Berhasil \\
\hline & Qwitz & $\begin{array}{l}\text { Aplikasi mampa } \\
\text { menampilkan quis, dain } \\
\text { masimg-masing jawabon } \\
\text { salah dan benar nya. }\end{array}$ & IEerhasil \\
\hline & Pindah seme & $\begin{array}{l}\text { Setelah quiz selesai, } \\
\text { muncul bwhew dan } \\
\text { ketika di klik scene akan } \\
\text { pindah ke mode simulasi }\end{array}$ & Bertusil \\
\hline \multirow{2}{*}{ Mode Simulasi } & Merakit konputer & $\begin{array}{l}\text { Objek konoenes } \\
\text { komputer dapat diangkat } \\
\text { dan dipindahkat unhak } \\
\text { dirskit }\end{array}$ & Berthasil \\
\hline & $\begin{array}{l}\text { Menampilkan } \\
\text { cavrus }\end{array}$ & $\begin{array}{l}\text { Aplikasi menumpillkan } \\
\text { caunws "berhusil" setalah } \\
\text { semua komponen selesai } \\
\text { dirakit }\end{array}$ & Berhasil \\
\hline
\end{tabular}

Setelah perancangan media pembelajaran selesai diimplementasikan di SMKN 3 Kota Bekasi, maka peneliti mengumpulkan data sebagai acuan dalam menghitung tingkat keberhasilan media wakil yang mengerti Kompetensi Dasar (KD) materi pembelajaran bidang komputer. Pada pengisian kuesioner ini ada 5 responden dengan 10 pertanyaan. Para ahli materi terdiri dari (kepala sekolah: 1 orang, wakil kepala sekolah: 1 orang, dan 3 guru penyusun kurikulum KD). Tabel Likert hasil kuesioner dari para ahli materi terkait aspek isi materi pada aplikasi ini ditunjukkan pada tabel 3. Pertanyaan yang diajukan pada tabel 4 .

b) Kuesioner Respon Guru

Guru disini merupakan yang mengajar TKJ (Teknik komputer dan jaringan). Pada sekolah ini terdapat memiliki 10 orang guru, dengan 6 pertanyaan. Hasil dari kuesioner ini ditunjukkan pada tabel 5. Pertanyaan yang diajukan pada tabel 6 .

c) Kuesioner Respon Siswa

Pada pengisian kuesioner ini terdapat 30 responden (siswa) dengan 8 pertanyaan, berikut hasil kuesioner dari para siswa kelas XI terkait tampilan, informasi, dan kemudahan media pembelajaran ini ditunjukkan pada tabel 7. Daftar pertanyaan pada tabel 8.

Tabel 3. Skala Likert kepada ahli materi

\begin{tabular}{|c|c|c|c|c|c|c|c|c|c|c|c|}
\hline \multicolumn{12}{|c|}{ Kuesioner Validasi Media Pembelajaran } \\
\hline \multirow{2}{*}{ No } & \multicolumn{4}{|c|}{ Skor } & \multirow{2}{*}{ N-Max } & \multicolumn{4}{|c|}{ Jumlah skor } & \multirow{2}{*}{ Jumlah } & \multirow{2}{*}{$\begin{array}{c}\text { Persentasi } \\
\text { (\%) }\end{array}$} \\
\hline & 1 & 2 & 3 & 4 & & 1 & 2 & 3 & 4 & & \\
\hline 1 & & & 1 & 4 & \multirow{10}{*}{20} & 0 & 0 & 3 & 16 & 19 & 95 \\
\hline 2 & & & 2 & 3 & & 0 & 0 & 6 & 12 & 18 & 90 \\
\hline 3 & & & 4 & 1 & & 0 & 0 & 12 & 4 & 16 & 80 \\
\hline 4 & & & & 5 & & 0 & 0 & 0 & 20 & 20 & 100 \\
\hline 5 & & 1 & 2 & 3 & & 0 & 2 & 6 & 12 & 20 & 100 \\
\hline 6 & & & & 5 & & 0 & 0 & 0 & 20 & 20 & 100 \\
\hline 7 & & 1 & & 4 & & 0 & 2 & 0 & 16 & 18 & 90 \\
\hline 8 & & & 1 & 4 & & 0 & 0 & 3 & 16 & 19 & 95 \\
\hline 9 & & & 4 & 1 & & 0 & 0 & 12 & 4 & 16 & 80 \\
\hline 10 & & & 1 & 4 & & 0 & 0 & 3 & 16 & 19 & 95 \\
\hline \multicolumn{11}{|c|}{ Jumlah } & 750 \\
\hline
\end{tabular}

pembelajaran VR ini, data yang peneliti peroleh adalah sebagai berikut:

\section{a) Kuesioner Ahli Materi}

Tabel 4. Daftar Pertanyaan kepada ahli materi

Ahli materi disini merupakan guru yang berkompeten (pengajar komputer), selain itu juga kepala sekolah, dan 


\begin{tabular}{|c|c|c|}
\hline Aspek & No & Indikator \\
\hline \multirow{5}{*}{ Isi } & 1 & $\begin{array}{l}\text { Kesesuaian media pembelajaran } \\
\text { terhadap silabus }\end{array}$ \\
\hline & 2 & $\begin{array}{lcr}\text { Kesesuaian materi pada media } \\
\text { pembelajaran } \\
\text { mengajar }\end{array}$ \\
\hline & 3 & $\begin{array}{l}\text { Kesesuaian materi pembelajaran } \\
\text { dengan indikator yang akan dicapai } \\
\text { siswa }\end{array}$ \\
\hline & 4 & $\begin{array}{l}\text { Manfaat materi untuk penambahan } \\
\text { wawasan pengetahuan siswa }\end{array}$ \\
\hline & 5 & $\begin{array}{l}\text { Kemudahan dalam memahami materi } \\
\text { pembelajaran }\end{array}$ \\
\hline \multirow{5}{*}{ Konstruksi } & 1 & $\begin{array}{l}\text { Kesesuaian materi pembelajaran } \\
\text { dengan tingkat kemampuan siswa }\end{array}$ \\
\hline & 2 & $\begin{array}{l}\text { Urutan penyajian dalam materi } \\
\text { pembelajaran }\end{array}$ \\
\hline & 3 & $\begin{array}{l}\text { Mengenai kelengkapan informasi } \\
\text { dalam media pembelajaran ini }\end{array}$ \\
\hline & 4 & $\begin{array}{l}\text { Mengenai sistematika } \\
\text { pembelajaran ini }\end{array}$ \\
\hline & 5 & $\begin{array}{l}\text { Bagaimana media pembelajaran ini } \\
\text { akan memberikan motivasi belajar } \\
\text { pada siswa }\end{array}$ \\
\hline
\end{tabular}

\begin{tabular}{ll}
\hline Keterangan : & \\
$1=$ Tidak Baik & $3=$ Baik \\
2 = Kurang Baik & $4=$ Sangat Baik
\end{tabular}

Tabel 5. Skala Likert respon guru

\begin{tabular}{|c|c|c|c|c|c|c|c|c|c|c|c|}
\hline \multicolumn{12}{|c|}{ Kuesioner Validasi Media Pembelajaran } \\
\hline \multirow{2}{*}{ No } & \multicolumn{4}{|c|}{ Skor } & \multirow{2}{*}{ N-Max } & \multicolumn{4}{|c|}{ Jumlah skor } & \multirow{2}{*}{ Jumlah } & \multirow{2}{*}{$\begin{array}{c}\text { Persentasi } \\
\quad(\%)\end{array}$} \\
\hline & 1 & 2 & 3 & 4 & & 1 & 2 & 3 & 4 & & \\
\hline 1 & & 2 & 4 & 4 & \multirow{6}{*}{40} & 0 & 4 & 12 & 16 & 32 & 80 \\
\hline 2 & & 3 & 3 & 4 & & 0 & 6 & 9 & 16 & 31 & 77,5 \\
\hline 3 & & & 7 & 3 & & 0 & 0 & 21 & 12 & 33 & 82,5 \\
\hline 4 & & & 2 & 8 & & 0 & 0 & 6 & 32 & 38 & 95 \\
\hline 5 & 1 & 2 & 1 & 5 & & 1 & 4 & 3 & 20 & 28 & 70 \\
\hline 6 & & & 4 & 6 & & 0 & 0 & 12 & 24 & 36 & 90 \\
\hline \multicolumn{11}{|c|}{ Jumlah } & 495 \\
\hline \multicolumn{11}{|c|}{ Rerata Total (\%) } & 82,5 \\
\hline
\end{tabular}

Tabel 6. Daftar pertanyaan kepada guru

\begin{tabular}{|c|l|l|}
\hline No & \multicolumn{3}{|c|}{ Pertanyaan } \\
\hline $\mathbf{1}$ & Tampilan pada media pembelajaran ini \\
\hline $\mathbf{2}$ & $\begin{array}{l}\text { Kemudahan dalam menggunakan media } \\
\text { pembelajaran ini }\end{array}$ \\
\hline $\mathbf{3}$ & $\begin{array}{l}\text { Kesesuaian objek 3D dari komponen-komponen } \\
\text { komputer }\end{array}$ \\
\hline $\mathbf{4}$ & $\begin{array}{l}\text { Kemampuan media pembelajaran ini dalam } \\
\text { meningkatkan motivasi belajar }\end{array}$ \\
\hline $\mathbf{5}$ & $\begin{array}{l}\text { Kemampuan media pembelajaran untuk membantu } \\
\text { mempelajari komponen komputer beserta cara } \\
\text { merakitnya }\end{array}$ \\
\hline $\mathbf{6}$ & $\begin{array}{l}\text { Kejelasan informasi yang ada pada media } \\
\text { pembelajaran ini }\end{array}$ \\
\hline
\end{tabular}

\begin{tabular}{ll}
\hline Keterangan : & \\
$1=$ Tidak Baik & $3=$ Baik \\
$2=$ Kurang Baik & $4=$ Sangat Baik
\end{tabular}

Tabel 7. Skala Likert respon siswa

\begin{tabular}{|c|c|c|c|c|c|c|c|c|c|c|c|}
\hline \multicolumn{12}{|c|}{ Kuesioner Validasi Media Pembelajaran } \\
\hline \multirow{2}{*}{ No } & \multicolumn{4}{|c|}{ Skor } & \multirow{2}{*}{ N-Max } & \multicolumn{4}{|c|}{ Jumlah skor } & \multirow{2}{*}{ Jumlah } & \multirow{2}{*}{\begin{tabular}{|c} 
Persentasi \\
$(\%)$
\end{tabular}} \\
\hline & 1 & 2 & 3 & 4 & & 1 & 2 & 3 & 4 & & \\
\hline 1 & 1 & & 14 & 15 & \multirow{8}{*}{120} & 1 & 0 & 42 & 60 & 103 & 85,8333333 \\
\hline 2 & & 2 & 16 & 12 & & 0 & 4 & 48 & 48 & 100 & 83,3333333 \\
\hline 3 & 1 & & 11 & 18 & & 1 & 0 & 33 & 72 & 106 & 88,3333333 \\
\hline 4 & & 2 & 15 & 13 & & 0 & 4 & 45 & 52 & 101 & 84,1666667 \\
\hline 5 & & 1 & 13 & 16 & & 0 & 2 & 39 & 64 & 105 & 87,5 \\
\hline 6 & & 5 & 15 & 10 & & 0 & 10 & 45 & 40 & 95 & 79,1666667 \\
\hline 7 & & 3 & 11 & 16 & & 0 & 6 & 33 & 64 & 103 & 85,8333333 \\
\hline 8 & 1 & 2 & 15 & 12 & & 1 & 4 & 45 & 48 & 98 & 81,6666667 \\
\hline \multicolumn{11}{|c|}{ Jumlah } & 675,833333 \\
\hline & & & & & Rerata To & & & & & & 84,4791667 \\
\hline
\end{tabular}

Tabel 8. Daftar pertanyaan kepada siswa

\begin{tabular}{|c|l|}
\hline No & \multicolumn{1}{|c|}{ Pertanyaan } \\
\hline $\mathbf{1}$ & $\begin{array}{l}\text { Kemenarikan tampilan pada media pembelajaran } \\
\text { untuk dipelajari siswa }\end{array}$ \\
\hline $\mathbf{2}$ & $\begin{array}{l}\text { Kejelasan warna, jenis font, pada tulisan dalam } \\
\text { media pembelajaran ini }\end{array}$ \\
\hline $\mathbf{3}$ & $\begin{array}{l}\text { Kesesuaian materi pada media pembelajaran } \\
\text { dengan materi pokok pada Kompetensi Dasar (KD) }\end{array}$ \\
\hline $\mathbf{4}$ & $\begin{array}{l}\text { Kesesuaian materi yang disajikan dengan tujuan } \\
\text { pembelajaran yang ingin dicapai }\end{array}$ \\
\hline $\mathbf{5}$ & $\begin{array}{l}\text { Penyajian objek 3 dimensi dari komponen } \\
\text { komputer pada media pembelajaran }\end{array}$ \\
\hline $\mathbf{6}$ & $\begin{array}{l}\text { Kemampuan media pembelajaran ini dalam } \\
\text { meningkatkan motivasi belajar siswa }\end{array}$ \\
\hline $\mathbf{7}$ & $\begin{array}{l}\text { Fleksibilitas penggunaan media pembelajaran pada } \\
\text { saat dalam pembelajaran }\end{array}$ \\
\hline $\mathbf{8}$ & $\begin{array}{l}\text { Kemudahan media pembelajaran untuk memahami } \\
\text { materi yang disajikan }\end{array}$ \\
\hline \hline $\begin{array}{l}\text { Kelerangaul : } \\
\text { 1= lidak Baik 3=Buik } \\
2 \text { - Kurang Baik 4= Seutyal Buik }\end{array}$ \\
\hline
\end{tabular}

\section{SIMPULAN}

Setelah selesai melakukan pembuatan aplikasi, maka dapat diambil kesimpulan sebagai berikut:

Aplikasi Virtual Reality ini dibuat sebagai media belajar siswa dengan unsur materi pelajaran yang sesuai dengan materi pokok pada Kompetensi Dasar (KD) yang ada di SMKN 3 Kota Bekasi dapat dilihat dari hasil skala likert kepada ahli materi didapatkan hasil total $75 \%$. Repone guru terhadap aplikasi ini didapatkan dari kuesioner yang telah di berikan mendapatkan hasil total 
$82.5 \%$. Berdasarkan tingkat keberhasilan yang telah tercapai mengenai kejelasan objek 3D komponen komputer, kejelasan warna dan jenis font. Media Pembelajaran dengan Virtual Reality ini dapat digunakan sebagai salah satu metode dalam pembelajaran yang mampu meningkatkan motivasi serta ketertarikan siswa dapat dilihat pada hasil Skala Likert respon siswa $79.167 \%$. Dari segi tampilan dan kejelasan informasi yang baik, sehingga dapat memudahkan siswa untuk mempelajari komponen komputer dan membantu siswa dalam memahami cara merakitnya dengan didapatkan hasil total $84.479 \%$. Maka dapat disimpulkan dari hasil penelitian yang telah dilakukan, bawah pembuatan media pembelajaran merakit PC dengan teknologi virtual reality bisa menjadi salah satu solusi dalam mengantikan pembelajaran dengan cara konvensional.

\section{REFERENSI}

[1] A. Sujana, Pendidikan IPA teori dan praktik. 2014.

[2] A. Randi, Pemanfaatan Teknologi Virtual Reality Sebagai Media Pembelajaran Interaktif Untuk Sistem Tata Surya Berbasis Android. 2017.

[3] N. Z Zakiyan, E. Sinduningrum, and $\mathrm{H}$. Irfan, "Perancangan Media Pembelajaran Virtualisasi Masjidil Harram Dengan Virtual Reality," Pros. Semin. Nas. Teknoka, vol. 2, no. 2502, pp. 167--174, 2017.

[4] Servasius Vidiardi, "Pengembangan Museum Virtual Interaktif Menggunakan Teknologi Desktop Virtual Reality Pada Museum Ranggawarsita," Teknik, p. 30, 2015.

[5] A. Rachman, J. S. Informasi, F. T. Informasi, J. T. Informatika, and F. T. Informasi, "Pemanfaatan Teknologi 3D Virtual Reality Pada," J. IIm., vol. 3, no. 1, pp. 37-44, 2017.

[6] N. A. S. Berta Sihite, Febriliyan Samopa, "Penerapan Metode Finite State Machine Pada Game 'The Relationship,"' Inform. Mulawarman J. IIm. IImu Komput., vol. 11, no. 1, p. 14, 2016.

[7] S. Rabiah, "Penggunaan Metode Research and Development dalam
Penelitian Bahasa Indonesia di Pergurtuan Tinggi," Univ. Muslim Indones., vol. 1, no. April 2015, pp. 1-7, 2015.

[8] Hanafi, "Konsep Penelitian R \& D Dalam Bidang Pendidikan," Saintifika Islam. J. Kaji. Keislam., vol. 4, no. 2, pp. 129-150, 2017.

[9] K. Teguh Martono, "Augmented Reality sebagai Metafora Baru dalam Teknologi Interaksi Manusia dan Komputer," J. Sist. Komput., vol. 1, no. 2, pp. 60-64, 2011.

[10] A. Hendini, "PEMODELAN UML SISTEM INFORMASI MONITORING PENJUALAN DAN STOK BARANG," KHATULISTIWA Inform., vol. IV, no. 2, p. 107, 2016.

[11] G. Hamdi and Krisnawati, "Membangun Aplikasi Berbasis Android 'Pembelajaran Psikotes' Menggunakan App Inventor," J. DASI Vol. 12 No. 4 DESEMBER 2011, vol. 12, no. 4, pp. 37-41, 2011.

[12] W. Budiaji, "Skala Pengukuran dan Jumlah Respon Skala Likert (The Measurement Scale and The Number of Responses in Likert Scale)," IImu Pertan. dan Perikan., vol. 2, no. 2, pp. 127-133, 2013. 